\title{
Analysis of China's Agricultural Non-Point Source Pollution and Green Total Factor Productivity
}

\author{
Lei $\mathrm{Fu}^{1} \mathrm{Hao} \mathrm{Liu}^{2, *}$ Sidai $\mathrm{Guo}^{2}$
}

\author{
${ }^{1}$ School of Economics, Sichuan University, Chengdu, Sichuan 610065, China \\ ${ }^{2}$ School of Economics \& Management, Southwest University of Science and Technology, Mianyang, Sichuan 621010, \\ China \\ *Corresponding author. Email: guosidai@126.com
}

\begin{abstract}
Agricultural total factor productivity is an important indicator to measure and evaluate the quality of agricultural development and reform performance. Based on the panel data of 31 provinces and cities in Chinese Mainland from 2000 to 2017, this paper uses a comprehensive survey-based inventory analysis method to measure agricultural non-point source pollution in various regions, regards it as an undesired output, comprehensively uses common frontier technology and SBM (Slack Based Measure)Malmquist-Luenberger index model to measure the growth and decomposition of agricultural green total factor productivity, and builds a regression model to test the impact of urbanization on total factor productivity. The research shows: firstly, China's agricultural non-point source pollution has maintained a high emission intensity for a long time, especially in the west, which is significantly higher than other regions; from the perspective of sources, the contribution of livestock and poultry breeding exceeds 50\%. Secondly, the average annual growth rate of China's agricultural green total factor productivity reaches $5.61 \%$ during the sample plate period, and the development trend is decreasing from the east to the middle to the west to the northeast. The main driving force for growth is the advancement of agricultural technology, and the efficiency of agricultural technology has shown a negative growth. Thirdly, the development of urbanization has a significant positive impact on the growth of agricultural green total factor productivity. Based on the conclusions of the analysis, this paper puts forward suggestions for transforming the production relations of small farmers, accelerating the process of urbanization, and promoting the green development of agriculture.
\end{abstract}

\section{Keywords: non-point source pollution, agricultural total factor productivity, urbanization, influence}

\section{INTRODUCTION}

Since the reform and opening up, with the transfer of a large number of agricultural surplus labor, China's urbanization has progressed rapidly, the agricultural production has developed steadily, the total grain output has doubled, and the supply of major agricultural products and national food security have been fully guaranteed. However, under the production mode dominated by traditional family management, the extensive use of cultivated land and the deterioration of the ecological environment are increasingly constraining the sustainable development of agriculture. According to statistics, in 2017, the utilization rate of chemical fertilizers for the three major grain crops of

*Fund: The Soft Science Project of Sichuan Provincia Department of Science and Technology "Research on the Highquality Utilization of Sichuan Rural Land Resources from the Perspective of Rural Revitalization" (Project number: 20RKX0398). CLC Number: F323, Document Code: A rice, corn and wheat in China was only $37.8 \%$, and the utilization rate of pesticides was $38.8 \%$; the annual pollutant discharge of livestock and poultry nationwide has reached 3.8 billion tons, causing the rural ecological environment to continue to deteriorate. The 19th National Congress of the Communist Party of China proposed the implementation of the rural revitalization strategy, and issued the "Opinions on Innovating Systems and Mechanisms to Promote Agricultural Green Development", and formulated more stringent measures for agricultural resources and environmental regulations. Therefore, measuring and analyzing agricultural non-point source pollution and agricultural green total factor productivity and testing the influencing factors of total factor productivity under the premise of resource and environmental constraints are of great practical significance for promoting agricultural supply-side reform and achieving highquality agricultural development. 


\section{LITERATURE REVIEW}

In 1948, the United States Department of Agriculture economists Barton (G.T.Barton) and Cooper (M.R.Cooper) jointly published "The Relationship Between Agricultural Output and Input", which became the founding work of agricultural total factor productivity research. McMlian (1989) [1] and Fan (1991) [2] used traditional non-frontier methods to measure China's agricultural total factor productivity earlier. This non-frontier method doesn't consider the inefficiency of production technology and has certain defects. After the introduction of the production frontier model in the 1990s, the use of frontier methods to measure agricultural total factor productivity has gradually become the mainstream research method [3]. For example, Zhou Duanming (2009)[4] and Fu Minghui (2016)[5] adopted data envelopment analysis DEA-Malmquist index method to measure agricultural TFP; Zhang Le (2013)[6], Shi Changliang (2016)[7], Li Xiang (2018)[8], etc. all used the stochastic frontier production function (SFA) for measurement. These two methods are mostly used to decompose and analyze the growth of TPF from the aspects of technical progress and technical efficiency. Most results show that the main driving force for its growth comes from technical progress, and the contribution of technical efficiency is small. However, many scholars still have not considered the possible "insufficient quantity" of output and the problem of undesired output. Pan Dan (2013) [9], Han Haibin (2013) [10], Li Gucheng (2014) [11], Ge Pengfei (2018) [12], Yang Qian (2019) [13], etc. calculated agricultural non-point source pollution and the intensity of agricultural land nitrogen surplus as undesired output, and incorporated them into the measurement indicators of agricultural total factor productivity, more accurately reflecting the real performance of China's agricultural economic growth. However, due to the difference in estimation method (parametric method or non-parametric method), data selection (official data, survey data or regional data) and the setting of the production function (stochastic frontier production function or Cobb-Douglas production function), etc., the calculation results of agricultural total factor productivity are also quite different [14].

A large number of studies have shown that in the process of China's development of modern agriculture, the low efficiency of factor allocation is the key bottleneck affecting the growth of agricultural total factor productivity. Therefore, on the basis of measuring agricultural total factor productivity growth, many scholars have carried out research from the perspectives of rural financial development, foreign direct investment, rural infrastructure, agricultural informatization, urban-rural income gap, and food security, and investigated the mechanism of related influencing factors on agricultural TFP (Jing Shen et al., 2017[15]; Wang Yafei et al., 2018[16]; Deng Xiaolan et al., 2018[17]; Gao Yang et al., 2018[18]; Gao Fan et al., 2016[19]; Zhan Jintao et al., 2019[ 20]). According to Lewis' dual economic theory, the transfer of surplus agricultural labor between urban and rural areas is the key to realize economic transformation and development. Therefore, studying the impact of the transfer of rural surplus labor on the growth of agricultural total factor productivity in the context of urbanization is a focus that deserves attention. Some scholars have conducted a apriority research on it, for example, Li Shimei (2017) [21] tested the impact of rural labor transfer on agricultural TFP by region, Wu Xiaoxu (2019) [22] tested the impact of different industries and forms of urbanization on agricultural TFP and spatial spillover effects, and the results showed that the development of urbanization of labor transfer has a significant role in promoting agricultural TFP

The above research still has some shortcomings: First, the traditional calculation method of agricultural total factor productivity doesn't consider resource constraints and environmental impacts, and can't truly evaluate agricultural economic development performance; some studies have adopted single indicators such as the use of chemical fertilizers and pesticides, or the discharge of excrements of livestock to replace agricultural non-point source pollution, underestimating the impact on environmental pollution. Second, most studies don't consider the heterogeneity problem of the environment, technology, and resource endowments among different regions. The total factor productivity of agriculture is only measured under the common frontier standard, ignoring the influence of regional differences on the measurement results. Third, against the background that green development has become the main theme of economic development, there are relatively few studies examining the impact of rapid urbanization on agricultural total factor productivity under environmental constraints. In view of this, this paper first uses the unit survey evaluation method to measure the value of agricultural non-point source pollution in various regions, then uses the common frontier technology and the SBM-MalmquistLuenberger index model to calculate the total factor productivity and decomposition of agriculture in various provinces and cities from 2000 to 2017, analyzes the trend of China's regional agricultural total factor productivity from the perspective of regional differences and temporal and spatial characteristics, and uses the regression model to test the impact of urbanization on green total factor productivity, in order to provide policy advice and suggestions for promoting the transformation and upgrading of China's agricultural growth mode and achieving high-quality development. 


\section{THE STYLIZED FACTS OF CHINA'S AGRICULTURAL NON-POINT SOURCE POLLUTION}

\section{A. Calculation of agricultural non-point source pollution}

Agricultural non-point source pollution refers to various pollutants formed in agricultural and rural production and life, including chemical oxygen demand (CODcr), total nitrogen (TN) and total phosphorus (TP) and other waste discharges. Based on a comprehensive comparative analysis of existing accounting methods for agricultural non-point source pollution, this paper draws on the research results of Chen Minpeng, Lai Siyun [23] [24] and others, and selects the inventory analysis method based on comprehensive surveys to calculate agricultural non-point source pollution from four types of pollution-producing units: agricultural fertilizer, livestock breeding, farmland solid waste, and rural life. The list of pollution-producing units and their coefficients are shown in "Table I". The quantitative relationship between each pollution unit, the amount of pollutants produced and the amount of emissions, that is, the calculation formula for the amount of agricultural non-point source pollution emissions is:

$$
\sum_{i} E U_{i} \rho_{i}\left(1-\mu_{i}\right) C_{i}
$$

$$
P I=E / S
$$

In the formula, $E$ is the total discharge of agricultural non-point source pollution; $E U_{i}$ is the statistics of unit $\mathrm{i} ; \rho_{i}$ is the pollution intensity coefficient of unit $\mathrm{i} ; \mu_{i}$ is the utilization efficiency coefficient of unit i pollutants; the product of $E U_{i}$ and $\rho_{i}$ is the discharge of agricultural non-point source pollution, that is, the maximum range of pollution produced by agricultural production without adding factors such as resource recycling; $C_{i}$ is the emission coefficient of pollutants in unit $i$. The data of each pollution-producing unit comes from the official statistical yearbook, and the parameter values are obtained through extensive literature research and reference to the "Manual of Agricultural Source Coefficients for the First National Pollution Source Survey". At the same time, 31 provinces and cities are divided into eastern, central, western and northeast regions ${ }^{1}$.

Note: The division of regions adopts the division method of China's economic regions announced by the State Statistics Bureau in 2011. The "China Western Development, the Revitalization of Old

\section{B. The development trend and spatial distribution of agricultural non-point source pollution}

The impact of agricultural non-point source pollution on the ecological environment is mainly reflected in the discharge and emission intensity. The average national agricultural non-point source pollution emissions from 2000 to 2017 was 1.4358 million tons, the average emission intensity per unit area was 0.452 tons/ha., and the two indicators showed a completely consistent development trend. From 2001 to 2005, there was a rapid growth momentum. In the following two years, the scale of livestock and poultry breeding decreased, and agricultural non-point source pollution also decreased. In the 10 years from 2007 to 2016, nonpoint source pollution basically stabilized, and by 2017 it showed a sharp decline. This shows that the country's efforts to promote structural reforms on the agricultural supply side and the tough fight against agricultural nonpoint source pollution have begun to show results. As shown in "Fig. 1", from the perspective of spatial distribution, the evolution trend of the pollution intensity per unit area in the four regions shows a high consistency. Among them, the western region is significantly higher than other regions, the northeast region and the central region basically tend to overlap, and the eastern region is slightly higher than the northeast and central regions. From the perspective of the source of agricultural non-point source pollution, the chemical oxygen demand (CODcr) pollution mainly comes from the discharge of rural domestic sewage and the discharge of pollutants caused by livestock and poultry breeding. The pollution of total nitrogen (TN) and total phosphorus (TP) mainly comes from pollution caused by livestock and poultry breeding and overuse of chemical fertilizers; on the whole, the contribution of livestock and poultry breeding to non-point source pollution exceeds $50 \%$, at the same time, the impact of farmland fertilizer use can't be underestimated [18]
Industrial Bases in Northeast China, the Rise of the Central Region, and the Optimal Development of the Eastern Region" proposed in the regional coordinated development strategy in the report of the 19th National Congress of the Communist Party of China actually followed the "Four Regions" division method. 
TABLE I. LIST OF POLLUTION-PRODUCING UNITS AND CORRELATION COEFFICIENTS OF AGRICULTURAL NON-POINT SOURCE POLLUTION

\begin{tabular}{|c|c|c|c|}
\hline $\begin{array}{l}\text { Source of } \\
\text { pollution }\end{array}$ & $\begin{array}{c}\text { Pollution-producing unit } \\
\text { index }\end{array}$ & Influencing parameter & $\begin{array}{c}\text { Discharge } \\
\text { List }\end{array}$ \\
\hline $\begin{array}{l}\text { Agricultura } \\
1 \text { fertilizer }\end{array}$ & $\begin{array}{lr}\text { Agricultural } & \text { nitrogen } \\
\text { fertilizer, phosphate fertilizer, } \\
\text { compound r fertilizer } \\
\text { application conversion scalar }\end{array}$ & $\begin{array}{l}\text { Nitrogen and phosphorus content of compound fertilizer } \\
(\%) \text {; loss rate of nitrogen fertilizer and phosphate fertilizer } \\
\text { by region }(\%)\end{array}$ & $\mathrm{TN}, \mathrm{TP}$ \\
\hline $\begin{array}{l}\text { Livestock } \\
\text { and poultry } \\
\text { breeding }\end{array}$ & $\begin{array}{l}\text { Pigs, cattle, sheep, poultry } \\
\text { Number of pigs, sheep and } \\
\text { other livestock growing to } \\
\text { slaughter weight/livestock in } \\
\text { breeding at the end of the } \\
\text { year }\end{array}$ & $\begin{array}{l}\text { Annual excretion coefficient of livestock and poultry } \\
\text { manure and pollutants excreted (kg/head); utilization rate } \\
\text { of livestock and poultry manure and pollutant loss by } \\
\text { region }(\%)\end{array}$ & $\begin{array}{l}\text { CODcr, } \\
\text { TN, TP }\end{array}$ \\
\hline $\begin{array}{l}\text { Farmland } \\
\text { solid waste }\end{array}$ & $\begin{array}{l}\text { Beans, rice, corn, wheat, } \\
\text { vegetables, potatoes, oil } \\
\text { plants } \\
\text { Total output }\end{array}$ & $\begin{array}{l}\text { Output ratio of vegetable solid waste }(\%) \text {; straw to grain } \\
\text { ratio of crops }(\%) \text {; solid waste nutrient content and } \\
\text { pollution-producing coefficient }(\%) \text {; rate of straw nutrient } \\
\text { returning to field and loss rate under different utilization } \\
\text { methods }(\%) \text {; straw utilization structure in some areas }(\%)\end{array}$ & $\begin{array}{l}\text { CODcr, } \\
\text { TN, TP }\end{array}$ \\
\hline $\begin{array}{l}\text { Agricultura } \\
1 \text { life }\end{array}$ & Rural population & $\begin{array}{l}\text { Rural domestic sewage, feces and urine pollution- } \\
\text { producing coefficient }(\mathrm{kg} / \text { person) and loss rate }(\%)\end{array}$ & $\begin{array}{l}\text { CODcr, } \\
\text { TN, TP }\end{array}$ \\
\hline
\end{tabular}

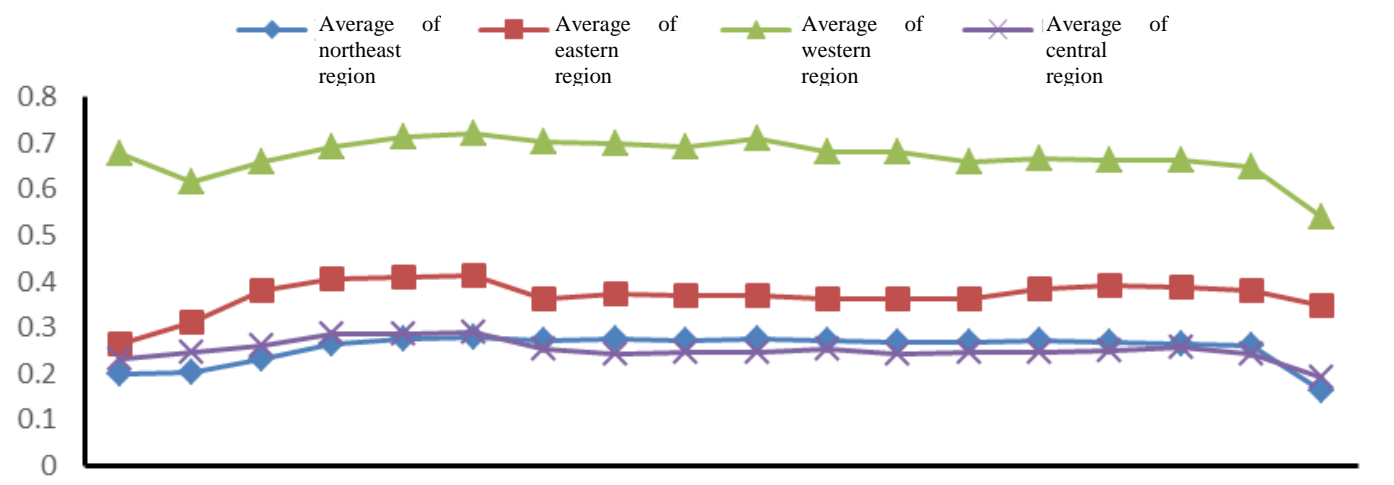

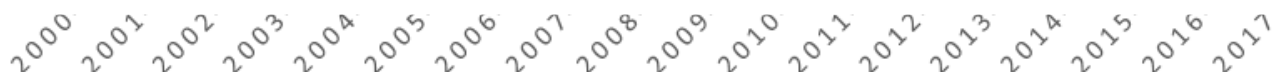

Fig. 1. Schematic diagram of the emission intensity of agricultural non-point source pollution in various regions across the country from 2000 to 2017.

\section{Calculation and ANAlysis OF China's REGIONAL AGRICULTURAL GREEN TOTAL FACTOR PRODUCTIVITY}

\section{A. Variable description and data processing}

This paper aims to examine the dynamic evolution of China's agricultural total factor productivity under environmental constraints, and selects the panel data of agricultural development indicators of 31 provinces and cities in Chinese Mainland from 2000 to 2017. The data comes from the "China Statistical Yearbook", "China Rural Statistical Yearbook", "China Agricultural Yearbook", "Compilation of 60 Years' Statistical Data of New China" and local yearbooks of various provinces and cities. Drawing lessons from existing research results, the selected agricultural input and output variables are as follows:
First, input indicators include six aspects: land, labor, machinery, fertilizer, draught animals and irrigation. Land input is calculated by adding up the total area of crop planting and aquaculture, and the unit is 1,000 hectares; labor input is calculated by the number of employees in farming, forestry, animal husbandry, side-line production and fishery, and the unit is 10,000 people; machinery input is expressed in terms of the total power of agricultural machinery, and the unit is 10,000 kilowatts; chemical fertilizer input is calculated based on the purity amount of nitrogen fertilizer, phosphate fertilizer, potash fertilizer and compound fertilizer, and the unit is 10,000 tons; the input of draught animals is calculated by the number of large livestock used for farming and transportation in agricultural production, and the unit is 10,000 heads; irrigation input is calculated based on the total amount of agricultural water used, and the unit is 100 million cubic meters. 
Second, output indicators include expected output and undesired output. The expected output is calculated based on the total output value of farming, forestry, animal husbandry, and fishery at constant prices in 2000 , with a unit of 10,000 yuan; the unexpected output is the total amount of agricultural non-point source pollution, with a unit of 10,000 tons. The descriptive statistical analysis of input-output indicators is shown in "Table II".

TABLE II.

DESCRIPTIVE STATISTICAL ANALYSIS OF INPUT-OUTPUT INDICATORS

\begin{tabular}{|c|c|c|c|c|c|}
\hline Index & Minimum & Maximum & $\begin{array}{c}\text { Average } \\
\text { value }\end{array}$ & $\begin{array}{l}\text { Standard } \\
\text { deviation }\end{array}$ & \begin{tabular}{|c} 
Number of \\
samples
\end{tabular} \\
\hline Total area of crops + aquatic products (thousand ha.) & 123.83 & 15150.28 & 5377.62 & 3731.10 & 558 \\
\hline $\begin{array}{l}\text { The total amount of agricultural chemical fertilizers converted into purity } \\
(10,000 \text { tons })\end{array}$ & 2.50 & 912.70 & 170.06 & 141.80 & 558 \\
\hline Number of agricultural draught animals $(10,000$ heads $)$ & 0 & 590 & 148.03 & 152.54 & 557 \\
\hline Total agricultural water (100 million cubic meters) & 5 & 562 & 117.74 & 99.70 & 558 \\
\hline $\begin{array}{l}\text { Total output value of farming, forestry, animal husbandry, and fishery } \\
\qquad(10,000 \text { yuan })\end{array}$ & 51.22 & 4613.72 & 1193.13 & 918.54 & 558 \\
\hline Total agricultural non-point source pollution discharge (10,000 tons) & 9.52 & 498.37 & 143.64 & 105.13 & 558 \\
\hline
\end{tabular}

\section{B. Research methods}

1) SBM model with undesired output: It assumes that $x, y^{b}$, and $y^{g}$ respectively represents the input vector, expected output vector, and undesired output vector of each decision-making unit; $s^{-}, s^{b}$, and $s^{g}$ respectively represents the slack variables corresponding to the input and output of each decisionmaking unit; $m$ and $s$ respectively indicate the types of input and output; $0<\rho^{*} \leq 1$, when $\rho^{*}=1$, it means that the decision-making unit is at the forefront side; When $\rho^{*}<1$, it means that there is still room for improvement in the decision-making unit; $\lambda$ is the adjusted weight. Therefore, the SBM model with undesired output is as follows:

$$
\begin{gathered}
\rho^{*}=\min \frac{1-\frac{1}{m} \sum_{i=1}^{m} \frac{s_{i}^{-}}{x_{i 0}}}{1+\frac{1}{s_{1}+s_{2}}\left(\sum_{r=1}^{s_{1}} \frac{s_{r}^{g}}{y_{r}^{g}}+\sum_{r=1}^{s_{2}} \frac{s_{r}^{b}}{y_{r}^{b}}\right)} \\
\text { s.t }\left\{\begin{array}{c}
x_{0}=X \lambda+s^{-} \\
y_{0}^{g}=Y^{g} \lambda-s^{g} \\
y_{0}^{b}=Y^{b} \lambda+s^{b} \\
s^{-} \geq 0, s^{g} \geq 0, s^{b} \geq 0, \lambda \geq 0
\end{array}\right.
\end{gathered}
$$

2) Meta-Frontier model of common frontier technology: The general idea of the Meta-Frontier model is to first construct a group boundary, and then integrate different groups to construct a common frontier boundary. This paper divides the decisionmaking unit into four group reference sets in the eastern, central, western and northeast regions, and constructs the front surface of the group separately; then the four regions are taken as a whole to construct a common front surface, and the Meta-frontier-
Malmquist method is used to further decompose the TFP measurement results. It assumes that the common technology set faced by the decision-making unit is:

$$
T^{\text {meta }}=\{(x, y) x \geq 0 ; y \geq 0 ; x \text { can produce } y\}_{(4}
$$
)

At this time, the production possibility set $P$ can be expressed as: $P^{\text {meta }}(x)=\left\{y \mid(x, y) \in T^{\text {meta }}\right\}$, and its upper bound is the common boundary.

Then, the distance function based on common technical efficiency is:

$$
0 \leq D^{\text {meta }}(x, y)=\inf \left\{\theta>0 \mid(y / \theta) \in P^{\text {meta }}(x)\right\} \leq 1_{(5)}
$$

It divides all decision-making units into $k(k>1)$ groups according to geographical area factors, then the technology set of $k$ group can be expressed as:

$$
T^{k}=\{(x, y) x \geq 0 ; y \geq 0 ; x \text { can produce } y\}_{(6)}
$$

Therefore, the production possibility set is: $P^{k}(x)=\left\{y \mid(x, y) \in T^{k}\right\}$, and its upper boundary is the group boundary. Therefore, the group distance function based on group technical efficiency is:

$$
0 \leq D^{k}(x, y)=\inf \left\{\theta>0 \mid(y / \theta) \in P^{k}(x)\right\} \leq 1
$$

At the same time, using the time series Malnquist index method proposed by Shestalova (2003) and the global Malnquist index method proposed by Pastor and Lovell (2005) can not only effectively avoid the problem of technical regress, but also solve the problem of error in the measurement results caused by the different base period settings, and it can also solve the problem of unsolvable linear programming. 


\section{China's regional agricultural green total factor productivity changes and decomposition}

It first adopts common frontier technology and SBM-Malmquist-Luenberger index model, and measures and calculates the change and decomposition value of agricultural total factor productivity in various regions of the country, as shown in "Table III" and "Table IV"; then, it calculates the geometric average of the total factor productivity changes and decomposition values at each time point in each region under different frontiers, and draws them into a line chart, as shown in "Fig. 2" and "Fig. 3". Based on a comprehensive analysis of the change pattern of agricultural total factor productivity in the four major regions, it selects crosssectional data at three key time nodes, uses ArcGIS 10.2 software to analyze its space, and takes the geometric average of total factor productivity changes as the classification standard; the total factor productivity change value of each province and city is divided into three types: decline, growth, and rapid growth; then, it draws a map of the evolution of the spatial pattern of agricultural total factor productivity changes in various provinces and cities across the country under the common frontier, as shown in "Fig. $4 "$.

TABLE III. CHANGES AND DECOMPOSITION OF AGRICULTURAL TOTAL FACTOR PRODUCTIVITY UNDER THE COMMON FRONTIER OF ALL REGIONS IN CHINA FROM 2000 TO 2017

\begin{tabular}{|c|c|c|c|c|c|c|c|c|c|}
\hline \multirow[b]{2}{*}{ Region } & \multicolumn{3}{|c|}{ ML } & \multicolumn{3}{|c|}{ EFFCH } & \multicolumn{3}{|c|}{ TECH } \\
\hline & $\begin{array}{c}2002- \\
2003\end{array}$ & $\begin{array}{c}2009- \\
2010\end{array}$ & $\begin{array}{c}2016- \\
2017\end{array}$ & $2002-2003$ & $\begin{array}{c}2009- \\
2010\end{array}$ & $\begin{array}{l}2016- \\
2017\end{array}$ & $\begin{array}{l}2002- \\
2003\end{array}$ & $\begin{array}{c}2009- \\
2010\end{array}$ & $\begin{array}{l}\text { 2016- } \\
2017\end{array}$ \\
\hline Beijing & 1.060 & 1.025 & 1.298 & 1.000 & 1.000 & 1.000 & 1.060 & 1.025 & 1.298 \\
\hline Tianjin & 0.840 & 1.727 & 1.136 & 0.832 & 1.000 & 1.000 & 1.011 & 1.727 & 1.136 \\
\hline Hebei & 1.054 & 1.040 & 1.221 & 1.037 & 1.040 & 1.026 & 1.017 & 1.000 & 1.190 \\
\hline Shandong & 1.145 & 1.031 & 1.069 & 1.145 & 1.031 & 1.019 & 1.000 & 1.000 & 1.050 \\
\hline Shanghai & 1.126 & 1.020 & 0.962 & 1.000 & 1.000 & 0.939 & 1.126 & 1.020 & 1.024 \\
\hline Jiangsu & 0.939 & 1.058 & 1.566 & 0.939 & 1.044 & 1.000 & 1.000 & 1.013 & 1.566 \\
\hline Zhejiang & 1.061 & 1.412 & 1.832 & 1.038 & 1.379 & 1.000 & 1.023 & 1.024 & 1.832 \\
\hline Fujian & 1.033 & 1.029 & 1.414 & 1.033 & 0.957 & 1.017 & 1.000 & 1.075 & 1.391 \\
\hline Guangdong & 1.025 & 1.023 & 1.069 & 1.017 & 1.016 & 1.015 & 1.007 & 1.006 & 1.053 \\
\hline Hainan & 0.943 & 1.000 & 1.307 & 0.682 & 1.000 & 1.000 & 1.383 & 1.000 & 1.307 \\
\hline Eastern region & 1.019 & 1.118 & 1.265 & 0.964 & 1.042 & 1.001 & 1.057 & 1.073 & 1.263 \\
\hline Shanxi & 1.041 & 0.992 & 1.117 & 1.041 & 0.992 & 1.068 & 1.000 & 1.000 & 1.046 \\
\hline Henan & 0.623 & 1.213 & 1.071 & 0.623 & 1.195 & 0.998 & 1.000 & 1.015 & 1.072 \\
\hline Anhui & 0.750 & 1.123 & 1.088 & 0.750 & 1.117 & 1.027 & 1.000 & 1.006 & 1.060 \\
\hline Hubei & 0.997 & 1.038 & 1.010 & 0.997 & 1.038 & 0.978 & 1.000 & 1.000 & 1.033 \\
\hline Hunan & 1.015 & 1.017 & 1.050 & 1.015 & 1.017 & 1.005 & 1.000 & 1.000 & 1.045 \\
\hline Jiangxi & 0.983 & 1.006 & 1.053 & 0.983 & 1.006 & 1.020 & 1.000 & 1.000 & 1.032 \\
\hline Central region & 0.886 & 1.062 & 1.064 & 0.886 & 1.059 & 1.016 & 1.000 & 1.003 & 1.048 \\
\hline Inner Mongolia & 0.916 & 1.054 & 1.016 & 0.908 & 1.054 & 0.992 & 1.009 & 1.000 & 1.024 \\
\hline Shaanxi & 1.005 & 1.088 & 1.044 & 1.005 & 1.088 & 0.999 & 1.000 & 1.000 & 1.045 \\
\hline Guangxi & 0.979 & 0.963 & 1.041 & 0.977 & 0.963 & 0.998 & 1.001 & 1.000 & 1.043 \\
\hline Gansu & 1.020 & 1.050 & 1.079 & 1.020 & 1.050 & 1.037 & 1.000 & 1.000 & 1.040 \\
\hline Qinghai & 1.047 & 1.028 & 1.061 & 1.033 & 1.028 & 1.015 & 1.013 & 1.000 & 1.045 \\
\hline Ningxia & 1.001 & 1.122 & 1.045 & 0.983 & 1.122 & 1.021 & 1.019 & 1.000 & 1.023 \\
\hline Xinjiang & 1.012 & 1.059 & 1.068 & 0.976 & 1.059 & 1.050 & 1.037 & 1.000 & 1.017 \\
\hline Guizhou & 1.033 & 1.014 & 1.063 & 1.033 & 1.014 & 1.011 & 1.000 & 1.000 & 1.051 \\
\hline Sichuan & 1.016 & 1.023 & 1.043 & 1.016 & 1.023 & 0.997 & 1.000 & 1.000 & 1.045 \\
\hline Yunnan & 1.031 & 1.013 & 1.058 & 1.031 & 1.013 & 1.009 & 1.000 & 1.000 & 1.049 \\
\hline Chongqing & 1.078 & 1.012 & 1.067 & 1.000 & 1.000 & 1.001 & 1.078 & 1.012 & 1.065 \\
\hline Tibet & 0.596 & 1.120 & 1.115 & 0.531 & 1.120 & 1.059 & 1.121 & 1.000 & 1.053 \\
\hline Western region & 0.968 & 1.045 & 1.058 & 0.947 & 1.044 & 1.016 & 1.023 & 1.001 & 1.042 \\
\hline Heilongjiang & 0.958 & 1.197 & 1.039 & 0.957 & 1.193 & 1.022 & 1.001 & 1.004 & 1.017 \\
\hline Jilin & 1.026 & 1.028 & 1.024 & 1.026 & 1.028 & 0.995 & 1.000 & 1.000 & 1.029 \\
\hline Liaoning & 1.041 & 1.022 & 1.108 & 1.041 & 1.022 & 0.994 & 1.000 & 1.000 & 1.114 \\
\hline Northeast region & 1.007 & 1.080 & 1.056 & 1.007 & 1.078 & 1.004 & 1.000 & 1.001 & 1.052 \\
\hline
\end{tabular}

a. Note: Due to limited space, only the calculation results under the common frontier for some years are listed, the same below. 
TABLE IV. CHANGES AND DECOMPOSITION OF AGRICULTURAL TOTAL FACTOR PRODUCTIVITY UNDER THE FRONTIERS OF THE COUNTRY AND EACH REGIONAL GROUP FROM 2000 TO 2017

\begin{tabular}{|c|c|c|c|c|c|c|c|c|c|c|}
\hline Index & Region & $\begin{array}{c}2000- \\
2001 \\
\end{array}$ & $\begin{array}{c}2002- \\
2003\end{array}$ & $\begin{array}{r}2004- \\
2005\end{array}$ & $\begin{array}{c}2006- \\
2007\end{array}$ & $\begin{array}{c}2008- \\
2009\end{array}$ & $\begin{array}{c}2010- \\
2011 \\
\end{array}$ & $\begin{array}{c}2012- \\
2013 \\
\end{array}$ & $\begin{array}{r}2014 \\
2015 \\
\end{array}$ & $\begin{array}{c}2016- \\
2017\end{array}$ \\
\hline \multirow{5}{*}{ ML } & The whole country & 1.072 & 0.985 & 1.043 & 1.101 & 1.124 & 1.103 & 1.049 & 1.088 & 1.176 \\
\hline & Eastern region & 1.111 & 0.987 & 1.088 & 1.072 & 1.271 & 1.129 & 1.034 & 1.131 & 1.265 \\
\hline & Central region & 1.009 & 0.956 & 1.016 & 1.090 & 1.096 & 1.140 & 1.061 & 1.046 & 1.136 \\
\hline & Western region & 1.079 & 0.995 & 1.023 & 1.125 & 1.046 & 1.071 & 1.049 & 1.058 & 1.144 \\
\hline & Northeast region & 1.043 & 1.002 & 1.037 & 1.128 & 1.051 & 1.080 & 1.079 & 1.152 & 1.102 \\
\hline \multirow{5}{*}{$\mathrm{EFFCH}$} & The whole country & 1.010 & 0.954 & 0.998 & 0.992 & 1.034 & 1.015 & 0.985 & 0.988 & 1.011 \\
\hline & Eastern region & 0.995 & 0.934 & 1.008 & 0.981 & 1.067 & 1.019 & 0.955 & 0.970 & 1.001 \\
\hline & Central region & 0.991 & 0.949 & 0.981 & 1.004 & 1.062 & 1.062 & 1.000 & 0.987 & 1.010 \\
\hline & Western region & 1.036 & 0.970 & 0.988 & 1.000 & 1.001 & 0.992 & 0.999 & 1.000 & 1.020 \\
\hline & Northeast region & 0.996 & 0.969 & 1.034 & 0.972 & 1.004 & 1.000 & 1.000 & 1.000 & 1.009 \\
\hline \multirow{5}{*}{ TECH } & The whole country & 1.061 & 1.033 & 1.046 & 1.110 & 1.088 & 1.087 & 1.065 & 1.101 & 1.163 \\
\hline & Eastern region & 1.117 & 1.056 & 1.078 & 1.092 & 1.191 & 1.108 & 1.082 & 1.166 & 1.263 \\
\hline & Central region & 1.018 & 1.008 & 1.035 & 1.086 & 1.033 & 1.073 & 1.061 & 1.059 & 1.124 \\
\hline & Western region & 1.042 & 1.026 & 1.036 & 1.125 & 1.045 & 1.079 & 1.050 & 1.057 & 1.122 \\
\hline & Northeast region & 1.047 & 1.034 & 1.003 & 1.160 & 1.047 & 1.080 & 1.079 & 1.152 & 1.092 \\
\hline
\end{tabular}

1) The overall situation of China's agricultural total factor productivity and its decomposition and changes: It can be seen from "Table III" that from 2000 to 2017 , the average annual growth rate of national agricultural total factor productivity considering environmental factors under the common frontier was 5.61\%; from the perspective of its decomposition, the technical progress index has an average annual growth rate of $7.42 \%$, while technical efficiency has not increased but declined, with an average annual decline of $1.69 \%$. This shows that during the sample period, the main driving force of China's agricultural total factor productivity growth comes from technical progress, which is a technology-induced growth, and the distortion of factor allocation restricts the improvement of technical efficiency. Judging from the evolution of the time series in "Fig. 1", the overall agricultural total factor productivity showed a growth trend, but the fluctuation range was large during the period, especially the negative growth in 2002-2003. It was mainly due to the substantial reduction in the total grain acreage across the country, only the production of bulk farmproducts decreased by $5.8 \%$ compared with the previous year. Since 2004, the Chinese government has implemented a series of favorable agricultural policies such as reduction or exemption of agricultural taxes and universal direct subsidies for grain-growing farmers, which have mobilized farmers' enthusiasm for agricultural production. At the same time, focusing on the transformation of production and operation methods, and increasing the construction of agricultural infrastructure and the use and promotion of agricultural technology, have greatly increased the contribution rate of agricultural science and technology, and promoted the rapid growth of agricultural total factor productivity for 7 consecutive years. The average annual growth rate reaches $9 \%$, and the growth rate reaches its peak in 2008-2009, which fully reflects the positive spillover effect of agricultural reform. After experiencing a short trough period from 2011 to 2012, the growth rate of agricultural total factor productivity rebounded rapidly again. This is closely related to the country's continuous strengthening of agricultural and rural pollution prevention, improvement of agricultural resources and the environment, and effective reduction of agricultural non-point source pollution. As shown in "Fig. 2" and "Fig. 3", China's agricultural total factor productivity index curve is basically the same as the technical progress index curve. The technical efficiency curve is always below it, and the efficiency change value is less than 1 in most periods, proving that technical progress is the source of total factor productivity growth, and technical efficiency plays an obstructive role. Since 2005 , the change curve of the technical progress index and the change curve of the technical efficiency index have basically changed in the opposite direction, indicating that the positive effect of agricultural technological progress on total factor productivity has effectively made up for the reverse effect of technical efficiency. 


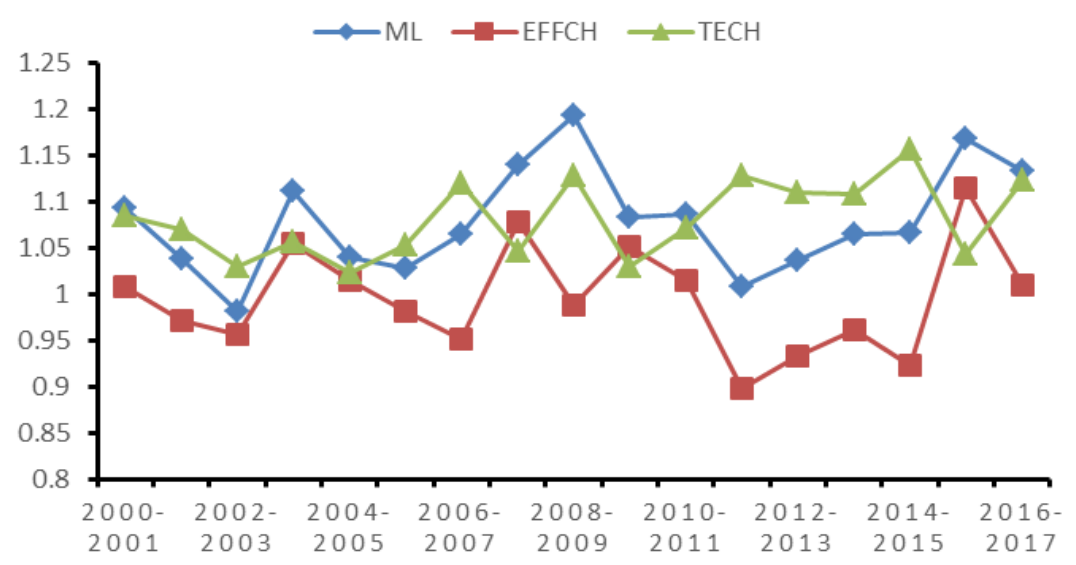

Fig. 2. Average distribution diagram of total factor productivity change and decomposition nationwide from 2000 to 2017 under the common frontier.

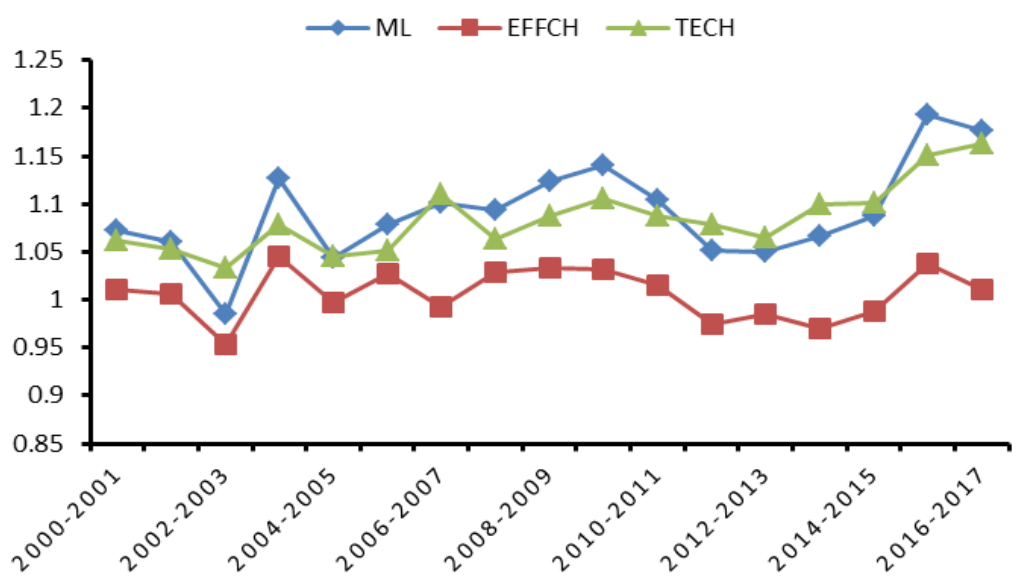

Fig. 3. Average distribution diagram of total factor productivity change and decomposition nationwide from 2000 to 2017 under the group frontier.

From a regional perspective, under the common frontier, the average annual growth of agricultural total factor productivity in the four major regions from 2000 to 2017 was positive. Among them, the eastern region had the fastest growth, with an average annual rate of $10.58 \%$. The central, western and northeast regions had relatively small differences, which were respectively $2.37 \%, 3.74 \%$, and $3.53 \%$. The eastern region has superior resource endowments, strong support from national policies and strong economic strength, driving the rapid growth of agricultural total factor productivity, and has always been in the position of agricultural "best practitioners" throughout the country. However, the provinces and cities in the central, western and northeast regions have suffered relatively large losses in agricultural efficiency due to their relatively lagging economic development. From the perspective of productivity decomposition, the average value of the technical efficiency index in the eastern region is positive, while the rest of the region is negative, confirming the positive correlation between the development of agricultural modernization and the improvement of technical efficiency. The average annual growth rate of the technical progress index in the central, western and northeast regions are relatively close, being $6.46 \%, 5.93 \%$, and $5.28 \%$ respectively. Among them, the central region is mostly flat area, which is convenient for large-scale agricultural operation, the popularity of agricultural mechanization is relatively high, and the growth rate of total factor productivity is relatively higher than that of the western and northeast regions. Under the cluster frontier, the total factor productivity of agriculture in the northeast region has shown a more rapid growth momentum than the eastern region, showing that the three provinces in the northeast of China have great internal differences. The provinces with better agricultural development have improved the overall level, but there is no greater comparability between regions.

2) The evolution of the spatial pattern of agricultural total factor productivity changes under the 
common frontier: Under the common frontier, the regions where the average annual growth rate of agricultural total factor productivity exceeds $10 \%$ are located in the eastern region, namely Beijing, Tianjin, Jiangsu and Zhejiang. The average value of changes in technical efficiency of the four provinces and cities is positive, which is mainly due to the strong economic development strength has supported the development of modern agriculture. From 2002 to 2003, 2009 to 2010, and 2016 to 2017, the mean values of agricultural total factor productivity changes in 31 provinces and cities across the country were $0.9712,1.0745$, and 1.1219 respectively, showing a clear upward trend. As shown in "Fig. 4", the overall spatial pattern of various provinces and cities has changed significantly. From 2002 to 2003, changes in total factor productivity of agriculture showed great differences in different regions. The total factor productivity of 11 provinces and cities in Tianjin, Jiangsu, Hainan, Henan, Anhui, Hubei, Jiangxi, Inner Mongolia, Guangxi, Tibet, and Heilongjiang was negative growth. Among them, due to the expansion of non-point source pollution caused by the rapid development of animal husbandry in Tibet, and the substantial reduction in crop production in Henan caused by rare floods, the decline in productivity reached more than $35 \%$; most provinces and cities had a growth rate below the average level, and they were spatially distributed in a "Y" shape; the growth rates above the average were Beijing, Shandong, Shanghai, Zhejiang and Chongqing, most of which are located in the eastern region. From 2009 to 2010, the total factor productivity of agriculture in 29 provinces and cities achieved positive growth. Among them, the number of provinces and cities with growth rates above the average expanded to 10 , and the provinces and cities that maintained growth levels below the average occupied "half of the country". From 2016 to 2017, all provinces and cities except Shanghai achieved positive growth in agricultural total factor productivity. Among them, 19 provinces and cities had a growth rate above the average, and the trend of seeking progress while maintaining stability of agricultural production was more obvious.
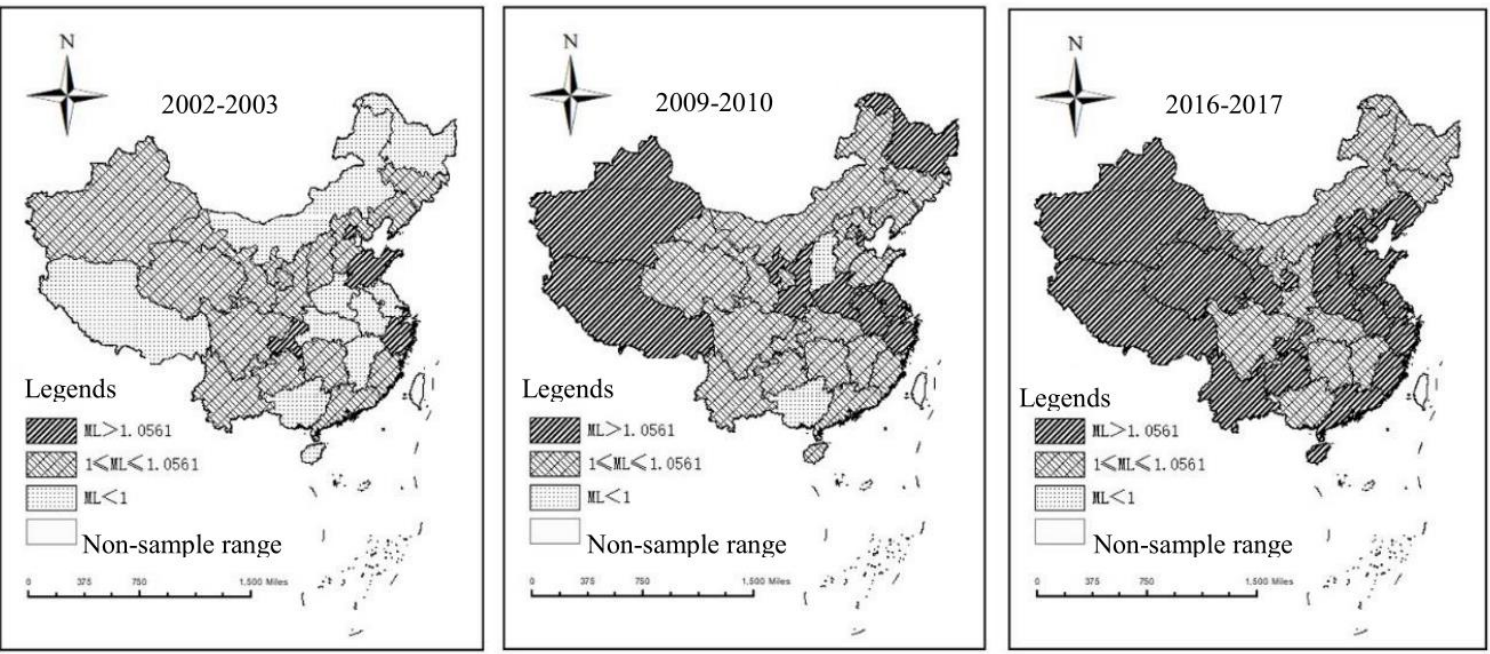

Fig. 4. The evolution of the spatial pattern of agricultural total factor productivity in different provinces and cities under the common frontier.

\section{ANALYSIS ON THE IMPACT OF URBANIZATION LEVEL ON AGRICULTURAL GREEN TOTAL FACTOR PRODUCTIVITY}

Urbanization is a process in which labor force is transferred to cities and its core is citizenization of population. Through the optimal allocation of labor factors between urban and rural areas, China's longterm "over-crowding" of small-peasant economic production conditions has been effectively transformed, which is conducive to the improvement of labor quality, greatly improving the income structure of farmers, creating conditions for the moderately large-scale and industrialized operation of agriculture, and promoting the growth of agricultural total factor productivity. But at the same time, limited by the urban-rural dual household registration system and related urban-rural public service policies, it is difficult for the majority of migrant workers to gain a foothold in the city, which is manifested in a semi-urbanized state of "leaving their hometowns without leaving the land", intensifying the vicious circle of small farmers part-time business and being satisfied with self-sufficient production, inevitably hindering land circulation and technology application and promotion, and becoming a major bottleneck in the process of agricultural green development and modernization. China's special urbanization process has both positive and negative 
impacts on agricultural development. Is the restricting factor stronger or the promoting factor larger? To this end, this paper constructs the following regression

$$
\ln t_{p p c a}, t=\beta_{0}+\beta_{1} \text { urban }_{i, t}+\beta_{2} \ln t f p c a_{i, t-1}+X_{i, t}+u_{i}+\lambda_{t}+\varepsilon_{i, t}
$$

Among them, $\ln t f p c a$ is the explained variable, which is the cumulative value of agricultural green total factor productivity with constant return to scale, which is processed in logarithm; urban is the core explanatory variable, representing the urbanization rate, expressed as the proportion of the city's permanent population to the total population; $X$ stands for control scalar; $u_{i}$ represents the unobservable province fixed effect; $\lambda_{t}$ is the time fixed effect; $\boldsymbol{E}_{i, t}$ is a random error term; $i=1,2, \ldots, 31$, representing 31 provinces (cities) in China; $t$ represents the year. The control variables mainly include the degree of agricultural mechanization (lnmech), which is represented by logarithmic values using the mechanical power per capita at the end of the year; the fiscal support for agriculture (gov) is measured by the proportion of the fiscal agricultural expenditure of each province (cities) in the total fiscal revenue; farmer's income structure (instr) is represented by the ratio of farmer's household operating income to total income; the urban-rural income ratio (indis) is expressed by the ratio of the per capita disposable income of urban model to examine the impact of urbanization rate on agricultural green total factor productivity:

residents to the per capita disposable income of rural residents; the agricultural industry concentration (aic), referring to Jia Xingmei and Li Ping (2014) [25], uses the average index of location entropy of 12 kinds of crops (cereals, beans, potatoes, oil plants, cotton, bast fibre plants, sugarcane, beet, tobacco, silkworm cocoons, tea, fruits) to measure; the per capita disposable income of rural residents (lndpi) is expressed as logarithmic value of the per capita disposable income of rural residents; the agricultural plantation structure (farm) is expressed as the proportion of the sown area of food crops to the total sown area of all crops; the disaster rate (disa) is measured by the proportion of the damage area in the sown area of crops. The per capita disposable income of urban residents and the per capita disposable income of rural residents are adjusted with the urban residents' price consumer index and the rural residents' price consumer index respectively in 2000. The above indicators and data come from "China Rural Statistical Yearbook", "China Statistical Yearbook", and "Compilation of 60 Years' Statistical Data of New China".

TABLE V. REGRESSION RESULTS OF FACTORS AFFECTING AGRICULTURAL GREEN TOTAL FACTOR PRODUCTIVITY

\begin{tabular}{|c|c|c|c|c|}
\hline \multirow[t]{2}{*}{ Variable } & (1) & (2) & (3) & (4) \\
\hline & Intfpca & Intfpca & Intfpca & Intfpca \\
\hline \multirow[t]{2}{*}{ urban } & $0.0284 * * *$ & $0.00827 * * *$ & $0.0107 * * *$ & $0.00899 *$ \\
\hline & $(0.00649)$ & $(0.00287)$ & $(0.00342)$ & $(0.00460)$ \\
\hline \multirow[t]{2}{*}{ lnmech } & & $-0.444 * *$ & $-0.457^{*}$ & -0.105 \\
\hline & & $(0.196)$ & $(0.237)$ & $(0.0735)$ \\
\hline \multirow[t]{2}{*}{ gov } & & $-0.0235^{*}$ & $-0.0442 * *$ & -0.00258 \\
\hline & & $(0.0142)$ & $(0.0214)$ & $(0.00480)$ \\
\hline \multirow[t]{2}{*}{ instr } & & -0.00429 & -0.00226 & 0.00195 \\
\hline & & $(0.00621)$ & $(0.00644)$ & $(0.00248)$ \\
\hline \multirow[t]{2}{*}{ indis } & & $0.346 * * *$ & 0.0337 & 0.0274 \\
\hline & & $(0.0763)$ & $(0.141)$ & $(0.0808)$ \\
\hline \multirow[t]{2}{*}{ aic } & & $-0.131 *$ & $-0.157 * *$ & -0.0403 \\
\hline & & $(0.0787)$ & $(0.0739)$ & $(0.0361)$ \\
\hline \multirow[t]{2}{*}{ lndpi } & & $1.008 * * *$ & 0.0746 & 0.106 \\
\hline & & $(0.231)$ & $(0.559)$ & $(0.248)$ \\
\hline \multirow[t]{2}{*}{ farm } & & 0.00804 & 0.0115 & 0.000526 \\
\hline & & $(0.0150)$ & $(0.0148)$ & $(0.00327)$ \\
\hline \multirow[t]{2}{*}{ disa } & & -0.000222 & -0.000232 & -0.000619 \\
\hline & & $(0.00106)$ & $(0.000911)$ & $(0.000937)$ \\
\hline \multirow[t]{2}{*}{ L. lntfpca } & & & & $0.859 * * *$ \\
\hline & & & & $(0.0682)$ \\
\hline \multirow[t]{2}{*}{ Constant } & $15.41 * * *$ & $7.443 * * *$ & $15.17 * * *$ & 1.105 \\
\hline & $(1.573)$ & $(2.862)$ & $(4.506)$ & $(2.634)$ \\
\hline $\begin{array}{c}\text { Time effect } \\
\text { Province effect }\end{array}$ & $\begin{array}{l}\text { No } \\
\text { No }\end{array}$ & $\begin{array}{l}\text { No } \\
\text { No }\end{array}$ & $\begin{array}{l}\text { Yes } \\
\text { Yes }\end{array}$ & $\begin{array}{l}\text { Yes } \\
\text { Yes }\end{array}$ \\
\hline Observed value & 527 & 527 & 527 & 496 \\
\hline R-squared & 0.264 & 0.508 & 0.536 & 0.848 \\
\hline Number of provinces & 31 & 31 & 31 & 31 \\
\hline
\end{tabular}

Note: The values in parentheses for Model 1 and Model 2 are robust standard errors, and values in parentheses for Model 3 and Model 4 are cluster standard errors; $* * *$ means bein significant at the $1 \%$ level, $* *$ means being significant at the $5 \%$ level, and $*$ means being significant at the $10 \%$ level. 
"Table V" reports the impact of urbanization rate on agricultural green total factor productivity. Model 1 shows that the urbanization rate has a significant positive impact on green total factor productivity. Each unit change in the urbanization rate causes a positive change of 0.0284 units in the growth rate of agricultural green total factors; after gradually adding control variables to Model 2, the urbanization rate still significantly promotes the green total factor productivity. In order to solve the problem of missing variables, Model 3 adds a two-way fixed effect model, avoiding two-way causality on the basis of Model 3, and treating the explanatory variable as one-period lag. The results all show that the process of urbanization has a positive role in promoting agricultural green total factor productivity, and it has good robustness. The process of urbanization is accompanied by a large amount of labor mobility, which realizes the optimal combination of labor, capital and other production factors in urban and rural areas, releases a huge demographic dividend for the development of China's industrialization, promotes the rapid improvement of economic strength, and creates favorable conditions for industry to feed back agriculture and cities to feed back to the countryside, which is reflected in the improvement of green total factor productivity in agriculture. This development trend is also consistent with the process of transformation from the dual economy of urban and rural areas to a unitary economy.

It can be seen from the table that the degree of agricultural mechanization, fiscal support for agriculture, and the degree of agglomeration of agricultural industries all have a significant negative impact on green total factor productivity. This shows that in the process of urbanization, the unrealistic pursuit of the scale effect of agriculture without the relationship of rural production can't improve the development level of agricultural productivity. As a large number of young and strong rural laborers enter the cities to work, problems such as the abandonment of agricultural land, agriculture by the elderly, and the fragmented management of small farmers have become increasingly prominent. The government tries to promote land circulation and capital to the countryside through incentive policies to form large-scale operations. The introduction of social capital has accelerated the development of new agricultural business entities and promoted the transformation of agricultural production methods. However, the nature of capital pursuit of profit not only squeezes out the already weak agricultural production profits, but also squeezes out the living space of vast small farmers, depriving farmers of their last living security. At the same time, due to the imperfect land transfer market mechanism, local governments are playing a leading role out of political considerations of their own performance, providing all-round policy support for capital to the countryside, tilting a large amount of financial funds to new business entities, gradually pushing small farmers out of the field of production and operation, and distorting the original intention of the land transfer policy. This kind of mandatory policy change ignores the fact that there are still 260 million small farmers in China and deviates from the current reality of rural production relations dominated by the small-peasant economy, laying hidden dangers for agricultural modernization and deserving attention.

\section{CONCLUSION}

Aiming at the limitations of traditional measurement of agricultural total factor productivity, based on the panel data of 31 provinces and cities in Chinese Mainland from 2000 to 2017, and on the basis of using inventory analysis to calculate agricultural non-point source pollution, this paper comprehensively uses the SBM model containing undesired output, the Global Malmquist Luenberger index model of common frontier technology and the time series Malmquist index model, measures the growth and decomposition of agricultural total factor productivity in China's provinces, cities and four major regions, and builds a regression model to examine the impact of urbanization rate on agricultural green total factor productivity.

Researches shows that: (1) From 2000 to 2017, China's agricultural non-point source pollution maintained a higher emission intensity for a long time. In recent years, under the guidance of agricultural green development policies, it has begun to show a significant downward trend. (2) China's agricultural total factor productivity considering environmental constraints is affected by agricultural environmental pollution and resource input, showing a tortuous growth state, with an overall annual growth rate of 5.61\%; among them, the technical progress index increases by $7.42 \%$ annually, while the technical efficiency decreases by $1.69 \%$ annually. It shows that technological progress is the fundamental driving force of agricultural growth, but there is a significant loss of efficiency in agricultural production, and the overall agricultural economic development is still dominated by extensive growth. From a regional perspective, the total factor productivity shows a decreasing trend in the easterncentral-western-northeast region, showing a clear step improvement trend over time. However, the eastern region has always been in the position of agricultural "best practitioners", and the technical efficiency index is also in positive growth. The central, western and northeast regions are facing the bottleneck of agricultural growth and the coordinated development of resources and environment, and urgently need to improve agricultural production and operation methods and raise the level of green agriculture. (3) The development of urbanization has a significant positive impact on the total factor productivity of agriculture, 
indicating that the transfer of agricultural surplus labor has improved the small-scale and fragmented smallscale production and management model to a certain extent, improving the overall quality of farmers, and promoting the improvement of agricultural productivity. However, large-scale agricultural operations have a negative impact on agricultural total factor productivity. For this reason, it's necessary to be alert to the negative effects of government-led capital going to the countryside.

Based on the above research and analysis, it implies the policy implications of improving technical efficiency, strengthening agricultural non-point source pollution control, and accelerating the process of urbanization. Under the current household contract responsibility system with remuneration linked to output, the small-scale production relationship that is compatible with the small-scale production mode of the family that meets the semi-subsistence consumption and semi-commercialization and dominates the rural areas has inherent discomfort with the application and promotion of modern agricultural technology, restraining a large number of rural laborers to a small piece of land, blocking the expansion of agricultural division of labor and the deepening of capital, becoming an important obstacle to agricultural modernization, and also bringing expensive transaction costs to the treatment of agricultural non-point source pollution. Therefore, to improve the total factor productivity of green agriculture, it's needed to start with reforming the production relations of small farmers in the context of the rural revitalization strategy. The specific path is to improve the rural market economy system on the premise of adhering to the rural collective ownership system, cultivate land transaction markets and promote the free flow of production factors such as land and labor between regions; then, it is to take the subdivision and clarification of property rights as the path, market demand as the guide, and the pursuit of profit maximization as the goal, optimize the allocation of land, labor, capital, technology and other elements in a corporate organization, establish a variety of agricultural management methods led by cooperative production, reconstruct the production relationship of "collective ownership + individual possession", achieve moderate scale operations based on the differences in resource endowments in various regions, and gradually realize the industrialization, scale and modernization of agriculture; efforts should be made to accelerate the equalization of public services, gradually establish a mechanism for farmers to withdraw from contracted land under the premise of protecting the rights and interests of farmers, and realize the urbanization of farmers. At the same time, it's also necessary to accelerate the pace of agricultural green development, continue to implement the zero-growth action of fertilizer and pesticide use, vigorously promote the resource utilization of livestock and poultry manure and the comprehensive utilization of agricultural film and straw, carry out crop rotation and fallow independently, and effectively strengthen the environmental protection and governance of agricultural resources. All provinces and cities should be based on actual conditions, improve their discrepant agricultural resource environmental protection and governance mechanisms, accelerate the diffusion of advanced experience and technology in the eastern region to the central and western regions, narrow the differences between regions, jointly build a resource-saving and environment-friendly agricultural green development system, and promote the agriculture to truly embark on a green and sustainable development track.

\section{References}

[1] McMillan J., Whalley J., Zhu L. J. The impact of China's economic reforms on agricultural productivity growth[J]. The Journal of Political Economy,1989,97(4):781-807.

[2] Fan S. G. Effects of technological change and institutiona reform on production growth in Chinese agriculture[J]. American Journal of Agricultural Economics, 1991, 73(2):266275.

[3] Li Hua et al. An Empirical Analysis on the Growth of Agricultural Total Factor Productivity of Farmers with Different Scales of Farmland Returning to Woodland - Based on the Survey Data of Rural Household Survey in the Loess Plateau[J]. Chinese Rural Economy, 2011(10): 36-43. (in Chinese)

[4] Zhou Duanming. Technological Progress, Technical Efficiency and China's Agricultural Productivity Growth - An Empirical Analysis Based on DEA[J]. The Journal of Quantitative \& Technical Economics, 2009(12):71-83. (in Chinese)

[5] Fu Minghui, Qi Chunjie. Factor Endowment, Technological Progress Bias and Agricultural Total Factor Productivity Growth - A Comparative Analysis Based on 28 Countries[J]. Chinese Rural Economy, 2016(12):76-90. (in Chinese)

[6] Zhang Le, etc. China's Agricultural Total Factor Productivity Growth: the Introduction of Changes in Allocation Efficiency - An Empirical Analysis Based on the Stochastic Frontier Production Function Method[J]. Chinese Rural Economy, 2013(3): 4-15. (in Chinese)

[7] Shi Changliang et al. Analysis of Regional Differences and Convergence of China's Agricultural Total Factor Productivity Growth - Based on the Fixed Effect SFA Model and Panel Unit Root Method[J]. Inquiry into Economic Issues, 2016(4):134-141. (in Chinese)

[8] Li Xiang et al. An Empirical Analysis of the Growth of Agricultural Total Factor Productivity in East China - Based on the Stochastic Frontier Production Function Model[J] Journal of Huazhong Agricultural University (Social Science Edition), 2018(06): 62-68+154. (in Chinese)

[9] Pan Dan et al. Research on China's Agricultural Total Factor Productivity Growth under the Constraints of Resources and Environment[J]. Resources Science, 2013, 35(7):1329-1338. (in Chinese)

[10] Han Haibin et al. Analysis of China's Agricultural Total Factor Productivity Growth and Convergence Under Environmental Constraints[J]. China Population, Resources and Environment, 2013, 23(3):70-76. (in Chinese) 
[11] Li Gucheng. Green Productivity Revolution in China's Agriculture: 1978-2008[J]. Economics (Quarterly), 2014(02): 537-558. (in Chinese)

[12] Ge Pengfei, Wang Songji, Huang Xiulu. China's Agricultural Green Total Factor Productivity Calculation[J]. China Population, Resources and Environment, 2018, 028(005):66-74. (in Chinese)

[13] Yang Qian, Wang Jue, Li Chao, Liu Xinpeng. Spatial Differentiation and Driving Factors of China's Agricultural Green Total Factor Productivity [J]. The Journal of Quantitative \& Technical Economics, 2019, 36(10): 21-37. (in Chinese)

[14] Pan Dan et al. Spatio-temporal Variation of China's Agricultural Total Factor Productivity Growth: a Literature-based Restudy [J]. Economic Geography, 2012, 32(7): 113-117. (in Chinese)

[15] Jing Shen, Xiao Longduo. The impact of rural formal and informal financial development on agricultural total factor productivity - An Empirical Study Based on China's Provincial Panel Data [J]. Jiangsu Social Sciences (4). (in Chinese)

[16] Wang Yafei, Zhang Yi, Liao Meng. The Impact of Foreign Direct Investment on Agricultural Total Factor Productivity: Mechanism of Action and Empirical Evidence[J]. Contemporary Economic Research, 2019(6). (in Chinese)

[17] Deng Xiaolan, Yan Weibo. Research on the Impact of Rural Infrastructure on Agricultural Total Factor Productivity[J]. Finance and Trade Research, 2018, v.29; No.178 (04): 40-49. (in Chinese)

[18] Gao Yang, Niu Ziheng. Agricultural Informatization, Spatial Spillover Effect and Agricultural Green Total Factor Productivity - Based on SBM-ML Index Method and Spatial Tobit Model[J]. Statistics \& Information Forum, 2018, 33(10) :67-76. (in Chinese)

[19] Gao Fan, Wang Yanan. How Does the Urban-Rural Income Gap Affect Total Factor Productivity?[J]. The Journal of Quantitative \& Technical Economics, 2016, v.33(01): 92-109. (in Chinese)

[20] Zhan Jintao, Xu Yujiao. Environmental Regulation, Agricultural Green Productivity and Food Security[J]. China Population, Resources and Environment, 2019,29(03):167-176. (in Chinese)

[21] Li Shimei, Yin Xiwen. Analysis of the Impact of China's Rural Labor Transfer on Agricultural Total Factor Productivity[J]. Journal of Agrotechnical Economics, 2017, 000(009): 4-13. (in Chinese)

[22] Wu Xiaoxu, Ge Pengfei, Xu Zhangyong. Urbanization and Agricultural Total Factor Productivity Improvement: Heterogeneity and Spatial Effect[J]. China Population, Resources and Environment, 2019, 29(05):152-159. (in Chinese)

[23] Lai Siyun et al. Non-point Source Pollution Investigation and Evaluation Method Based on Unit Analysis [J]. Journal of Tsinghua University (Natural Science Edition), 2004, 44 (9): 1184-1187. (in Chinese)

[24] Liang Liutao. Research on the temporal and spatial characteristics and evolution of rural ecological environment [D]. Nanjing: Nanjing Agricultural University, 2009. (in Chinese)

[25] Jia Xingmei, Li Ping. The changing characteristics of agricultural agglomeration and its relationship with agricultural economic growth - An empirical test of the changes in the spatial distribution of 12 types of crops in China[J]. Journal of China Agricultural University, 2014, 19(01): 209 -217. (in Chinese) 